\title{
El mensaje materialista de las ideologías del liberalismo, del socialismo y de la tecnología
}

\author{
The materialistic message of the ideologies of liberalism, \\ of socialism and technology
}

Johan Leuridan Huys*

Universidad de San Martín de Porres, Perú

\section{Resumen}

Analizamos las ideologías para demostrar que su raíz materialista está en el origen de muchos problemas en la sociedad. La economía -es decir, la producción y el consumo- define a la persona humana. El ser humano es un subproducto de la economía. Esta definición ofusca la conciencia que es la base de la ética y por lo tanto de la dignidad de la persona, porque la ciencia y la tecnología se dan siempre en relación con hombres libres cuyos encuentros tienen un significado cultural-ético. No podemos ser indiferentes a lo transcendente que no se puede verificar por experimentos o deducir de manera racional. La fe nos abre un horizonte distinto.

Palabras clave: ideología, liberalismo, socialismo, tecnología, economía, materialismo, conciencia, libertad, responsabilidad, relaciones morales, Dios.

\begin{abstract}
We analyze ideologies to demonstrate that their materialistic roots are at the origin of many problems in society. The economy -that is, production and consumption- defines the human person. The human being is a byproduct of the economy. This definition obscures the conscience that is the
\end{abstract}

Este es un artículo Open Access bajo la licencia Creative Commons Atribución-NoComercial-Compartirlgual 4.0

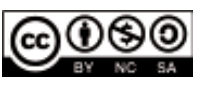


basis of ethics and therefore of the dignity of the person, because science and technology always occur in relation to free men whose encounters have a cultural-ethical meaning. We cannot be indifferent to the transcendent that cannot be verified by experiments or deduced rationally. Faith opens a different horizon for us.

Keywords: ideology, liberalism, socialism, technology, economy, materialism, conscience, freedom, responsibility, moral relations, God.

\section{El ser humano es un subproducto de la economía}

El socialismo en América Latina critica siempre al liberalismo como estrechamente ligado a la corrupción. Sin embargo, los últimos veinte años han demostrado que cuando el nuevo socialismo del siglo XXI llega al poder en esta región se va por el mismo camino. Todos los presidentes y muchos de sus funcionarios han terminado con juicios o se han aferrado al poder sin permitir elecciones limpias, como en Nicaragua, Cuba y Venezuela. En este caso, el socialismo se transforma en la dictadura del comunismo.

El liberalismo, el socialismo y la tecnología tienen la misma raíz y quieren organizar la sociedad a partir de una visión materialista.

Marx postulaba la preponderancia de las «fuerzas productivas» (la tierra, el transporte, la energía, la maquinaria, los instrumentos, etc.) y de «las relaciones de producción», reduciendo toda la historia a un único elemento: la lucha por los intereses económicos. La historia de los modos de producción y el avance de la tecnología indican la situación en la que se encuentra cada fase. La conciencia es un producto social al que el hombre se acerca con el aumento de la productividad. Marx suponía que cambiando el mundo material el hombre podía cambiarse a sí mismo. La realidad exterior transformada reaccionaría sobre él. Del cambio material saldrían hombres nuevos. Además, el marxismo propone la moral de la «lucha de clases». La moral se define en función del éxito de esta lucha. La verdad depende de la clase. La verdad está siempre de parte de la clase dominada, y la mentira de la clase que domina. Vista esta definición de la verdad, la 
lucha contra la otra clase justifica todos los medios. Estas acepciones extrañas de la verdad y de la moral se han divulgado, consciente o inconscientemente, como una evidencia indiscutible. La «lucha de clases» llevaría a un cambio estructural de la sociedad, donde al asumir la vanguardia el poder dictatorial automáticamente se resolverían todos los problemas, incluso los éticos. La historia probó lo contrario. La «lucha de clases» explica al ser humano, a la sociedad y a toda la historia; por lo tanto, no deja ningún espacio para una realidad transcendental. La libertad y las opiniones de la persona no juegan ningún papel.

John Locke -precursor de la revolución de París- es, sin duda, la figura principal en el inicio de la historia moderna. El liberalismo plantea las tres instituciones de libertad política (Gobierno, Congreso Nacional, Poder Judicial), elecciones libres, pluralidad de partidos, leyes protectoras de la libertad: la libertad social -donde tanto la vida privada como la familia son ajenas a toda norma e intervención del Estado- y la libertad económica del mercado. Después de Locke y Kant dominará la absoluta libertad de mercado durante la historia y su justificación la encontramos ya en el siglo XVII por parte del filósofo David Hume. La libertad es el juego de las interacciones económicas en el mercado. La justicia es producto del mercado. El hombre es producto del mercado. Milton lo describió de una manera exacta: en el mercado existe un mecanismo mágico que une diariamente a millones de individuos sin que tengan la necesidad de amar, ni siquiera de conversar entre ellos. Se trata de un mundo uniforme donde el otro no es una persona con quien se establece un encuentro, sino un objeto puro de consumo, de instrumentalizaciones. Los economistas ven al ser humano como alguien que tiene el deseo obsesivo y permanente de satisfacción material. El marketing crea la angustia de compra. La envidia, consecuencia de la comparación con las otras personas, refuerza esta angustia.

El pensamiento materialista del liberalismo y del socialismo ha promovido el impresionante desarrollo de la tecnología, pero sin control. La tecnología es la ideología de la actualidad. Las fronteras nacionales están perdiendo relevancia. Fueron el resultado de formaciones transnacionales y mercados financieros que combinaron necesidades nacionales con planificación y administración de carácter internacional. Hoy en día, la élite económica 
mundial, que posee más del ochenta por ciento del dinero, domina el mercado, la política y la cultura. Este sistema tecnológico-financiero global sin alma pretende constituirse actualmente como la única forma de sociedad. La consecuencia es la política de la neutralidad porque el poder político está sometido al poder económico. Jürgen Habermas observa que se le ha dado un carácter ideológico tanto a la ciencia como a la tecnología para eliminar la dimensión moral de la sociedad. Esta nueva ideología de la vida indica que los grandes valores son los valores materiales. La buena vida dependería entonces solo del desarrollo de la ciencia y de la técnica, y cualquier problema que se presente será por falta de desarrollo tecnológico. Actualmente se tiende a creer que todo incremento de tecnología constituye sin más un progreso, un aumento de seguridad, de utilidad y de bienestar. Se considera que la naturaleza está conformada por hechos externos que se pueden entender por métodos empíricos. Como consecuencia, el conocimiento se limitaría a una objetividad externa. La naturaleza es la base de nuestro conocimiento, mientras que la cultura es un invento del hombre y no tiene valor cognoscitivo.

\section{El poderoso mensaje materialista de las tres ideologías asfixia la conciencia de los seres humanos}

Debemos agradecer a la Modernidad por haber roto con un pasado donde un rey o emperador era propietario de los bienes, del pensamiento, de la planificación y de la organización; donde el matrimonio de su hija cambiaba las fronteras; donde la esclavitud y servidumbre eran normales. Por medio de la ciencia y del liberalismo, y posteriormente por medio del socialismo y de la tecnología, las condiciones materiales del ser humano cambiaron profundamente. Vemos la diferencia con la India, donde los pobres encuentran normal su situación dolorosa. El dolor no les llama a reclamar una mejor vida porque consideran que pertenecen a una casta cuya condición no tiene solución. El dolor de por sí no tiene conocimiento de algo mejor, no tiene exigencia ética, ni siquiera implícita como algunos pretenden.

La satisfacción de las necesidades materiales es imprescindible, aunque no suficiente para garantizar la felicidad. El progreso científico y tecnológico favorece a la humanidad, pero puede también volverse en contra de los 
seres humanos, amenazando su existencia misma porque falta la conciencia ética del daño ocasionado por el mal uso de la tecnología. Las ideologías sueñan solamente con producir riquezas materiales y armas, sin ningún control sobre las tecnologías. Ellas son culpables del deterioro ecológico global. El mensaje materialista nos ha traído los contaminantes atmosféricos, la contaminación por los residuos, la conversión de la Tierra en un inmenso depósito de porquería, el agotamiento del agua y el mar lleno de plásticos. Este mensaje es un crimen contra la humanidad. Los científicos han dado un ultimátum de diez años para cambiar las energías del carbón, del petróleo y del gas.

Se entiende la emancipación de la vida como una actividad a partir de la razón instrumental. El desarrollo técnico desprovisto de una dimensión interna es la causa de la degradación cultural. La élite tecnócrata y las ideologías materialistas eliminan toda referencia a los valores espirituales. Aparece la persona egoísta que solo busca el dinero para lograr goces materiales. ¿A dónde llevó este dominio tecnológico del mundo sin referencia a los valores espirituales? A la destrucción del ambiente, trata de personas, narcotráfico, paraísos fiscales sin pago de impuestos, monopolios, pandillas, feminicidios, bullying en los colegios, etc.

Otro grave problema es la corrupción. ¿Cuánto dinero de individuos de todos los países está colocado en los paraísos financieros sin pagar impuestos? ¿Cuánto dinero desaparece en la corrupción de los contratos y compras? ¿Cuánto dinero se invierte en armamento, en viajes inútiles al espacio? ¿Una autoridad corrupta puede hacer una correcta distribución de la riqueza?

¿Acaso los países ricos no conocen también el cinismo, la indiferencia y los suicidios? En Perú, Guatemala, Filipinas y Albania (países en vías de desarrollo), cada año se suicida una de cada cien mil personas. En países ricos como Suiza, Francia, Japón, Nueva Zelandia, Corea del Sur, Bélgica, Rusia, Austria y Dinamarca anualmente se quitan la vida veinticinco de cada cien mil personas. El progreso no es solo material.

La periodista Jennifer Tejada Dewar informa que veinticinco millones de mujeres en la Unión Europea (UE) fueron víctimas de violencia machista 
en el año 2014, principalmente en Suecia, Finlandia, Dinamarca, Francia e Inglaterra. En otros países de la UE no existen la conciencia ni la libertad de manifestarse como en los mencionados. En las comisarías se burlan de la mujer que presenta una denuncia. La violencia contra la mujer existe también en China y se considera que India es el peor país en el mundo en relación con este tema. Se necesita un ministerio de la familia en cada nación.

A pesar de los ingentes aportes científicos y tecnológicos de la Modernidad que permitieron el crecimiento masivo y el sostenimiento de gran parte de la población mundial, el siglo XX conoció dos guerras mundiales con setenta millones de muertos, a causa del comunismo hubo ciento veinte millones de muertos, Hiroshima, Gulag, Auschwitz, Irak, las guerras de descolonización y una carrera armamentista de las superpotencias.

Los genocidios en el último siglo han sido producto de la fe fanática en las ideologías del liberalismo y del socialismo. Como dice Chris Hedges (2008), periodista estadounidense ganador del Pulitzer, todo conocimiento que pretende ser absoluto se vuelve una forma de fe. Es posible destruir a millones de personas, y es posible destruir a la humanidad.

A fines del siglo $\mathrm{XX}$ se abrió un debate sobre el fracaso del socialismo y del liberalismo. El cuestionamiento de la razón por la Posmodernidad relativizó también las ideologías que ofrecen soluciones definitivas. Las ideologías pretenden conocer toda la realidad y proponen «soluciones» a partir de sus esquemas, desconociendo los límites de la razón y de sus planteamientos. Sin embargo, no se puede negar que cada ideología hace un aporte importante. El liberalismo enseñó que la riqueza es producto de la iniciativa privada en el mercado y el socialismo enseñó que todos necesitan una protección del Estado para la seguridad y la buena distribución de la riqueza.

La élite de la tecnología decide a dónde van las inversiones. Los otros países no pueden competir y están obligados a buscar dichas inversiones. Un país como Bélgica no cobra impuestos a las empresas extranjeras que invierten en su territorio. Como dice Harari (2015), la inteligencia artificial no es neutra. Los logaritmos no son neutros. El Estado no puede intervenir 
en las familias por el derecho a la libertad de opinión y la variedad de sus manifestaciones, pero el hecho de que no pueda imponer una concepción de la vida facilita a los logaritmos inmiscuirse en el ámbito privado y adueñarse de las opiniones, gustos y costumbres. En realidad, la vida privada no está separada de la mentalidad tecnócrata porque el dinero monopoliza el derecho de enseñar en todos los medios: diversión, telenovelas, reality- $T V$, deportes, canciones sin sentido, modas, pornografía, noticias falsas, ejemplos de vidas superficiales, etc.

Uno no escoge la ideología de la tecnología, como en los casos del liberalismo y del socialismo, sino que uno está capturado. El mundo tecnológico deshumaniza a las personas. Todo se convierte en dinero. La élite dicta la forma de estar en el mundo y el hombre adquiere la obsesión de ambicionar, de comprar y de divertirse, perdiendo el verdadero sentido de la vida. Para establecer un matrimonio la conversación es solo sobre las condiciones materiales. La educación de los hijos se dificulta por el uso obsesivo de los juegos electrónicos que la nueva ideología impone. Como ya no existe una conciencia del bien se pierde la confianza entre las personas. La consecuencia es la multiplicación de reglamentos y juicios. La globalización de la economía y de las finanzas transciende los poderes y las culturas nacionales. Ningún pueblo puede aislarse sin correr el riesgo de la marginación total y de volverse irrelevante.

La revolución de París formuló los derechos humanos que se promovieron a nivel internacional con la fundación de la ONU en 1948. Sin embargo, las ideologías hacen depender las actitudes de leyes o estructuras. Este acercamiento es consecuencia de un pensamiento que considera a la materia como la totalidad de la realidad. La materia manda porque no hay otra cosa. El espíritu es producto de la materia. La verdad no está en el ego. Uno debe deshacerse de normas recibidas. La exterioridad ubica y limita al hombre en el mundo sensible. Desde este punto de vista no queremos algo porque es un bien, sino que es un bien porque nosotros lo consideramos como un bien.

El nuevo orden tecnológico exige que los seres humanos dejen de sentirse como tales y se resignen a ser pobres egoístas aislados. La filósofa alemana Hannah Arendt escribía: 
Lo que es enojoso en las teorías nuevas no es que sean falsas, sino que puedan llegar a ser verdaderas. Si es verdad que el hombre no es un egoísta por naturaleza, no es menos verdad que el adiestramiento jurídico y el del mercado crean el contexto cultural ideal que permite que el egoísmo sea la forma habitual del comportamiento humano. (como se citó en Michéa, 2007, p. 203)

Por reducir al ser humano a producción y consumo, se pierde el valor de la persona en sí misma, su dignidad y también su solidaridad con los demás. Se prueba esta realidad en la violencia contra la Tierra. Nietzsche (2017) predijo la nueva cultura. El bien y el mal son valores relativos. Hay que amar lo presente. El individualismo, el egoísmo y la envidia de la Posmodernidad han traído mucha incertidumbre, indiferencia, falta de respeto, la desconfianza para iniciar un matrimonio, el bullying en los centros educativos, la corrupción en el Estado y en las empresas. Maalouf (2019) se pregunta:

Si las disparidades [socioeconómicas] son alarmantes, no es ya porque se corra el riesgo de que traigan consigo levantamientos planetarios, sino porque la desaparición de la brújula ética que representa el principio de igualdad contribuye en todos y cada uno de nuestros países, y también para la humanidad entera, a la desintegración del tejido social. (p. 212)

Los valores económicos prevalecen sobre la ética. El gran desarrollo de las empresas transnacionales y del mercado financiero global los vuelve cada vez más independientes de la intervención humana. Se reemplaza la moral por las bolsas y por el mercado, por producción y por consumo. Ya no hay formación de una conciencia personal. Los derechos humanos y todas las obligaciones ya no están en la conciencia, sino que pretenden estar en las leyes. La conciencia ya no obliga, lo hacen las leyes y el Poder Judicial mediante la coacción. No hay espacio para decisiones libres a partir de valores que broten de la conciencia personal.

Luc Ferry (2006) cuestiona al materialismo con la siguiente pregunta:

¿Para qué sirven nuestras protestas si están inscritas de toda eternidad en la realidad de la misma manera como las cosas a las cuales se oponen? Los materialistas niegan toda forma de 
transcendencia, sin darse cuenta de que su afirmación por la infraestructura que explicaría todo es onto-teológica. El materialismo no puede presentar una moral. Con más razón la libertad transciende las ideologías y sobre todo la ideología marxista que algunos, por ignorancia, consideran ciencia. El materialismo es aceptable cuando todo funciona bien, pero cuando surgen enfermedades, guerras, accidentes, etc., el materialista recurre a la libertad para ver cómo puede intervenir.

El materialista manifiesta que estamos determinados por la historia, pero al mismo tiempo nos invita a la emancipación y a la revolución. (p. 264)

\section{La decisión ética es el sentido de la vida}

Actualmente se tiende a creer que todo incremento de poder constituye sin más un signo de bienestar, como si el bien y la verdad brotaran espontáneamente del mismo poder tecnológico y económico. El hecho es que el hombre moderno no está preparado para utilizar el poder con acierto, porque el inmenso crecimiento tecnológico no ha estado acompañado de un desarrollo del ser humano en responsabilidad, valores y conciencia (Francisco, 2015, pp. 81-82). Se ha eliminado la pregunta por el bien espiritual y la conciencia personal.

En primer lugar, las ideologías se consideran autónomas y definen el bien en función del desarrollo material. Sin embargo, el conocido filósofo Jürgen Habermas aclaró la distinción fundamental entre trabajo y acción comunicativa, superando la reducción de las relaciones de producción a la dimensión de las fuerzas productivas hecha por el materialismo histórico. El desarrollo de estas fuerzas puede contribuir a la liberación moral del hombre, pero no la causa por sí mismo, ni siempre la ayuda. Mientras que la acción técnica exige aprendizaje de las ciencias y de las técnicas, la acción comunicativa exige apropiarnos de las normas morales y configurar nuestra personalidad. La realización de la buena vida o de la felicidad no puede hacerse desde la técnica, sino desde la comunicación moral. También existen las relaciones entre los seres humanos y no solo la relación con la producción material (Habermas, 2000, p. 20). 
El sociólogo Ralf Dahrendorf observa que las instituciones de la libertad (las elecciones, los tres poderes del Estado y la economía de mercado) son como estructuras de vidrio y hormigón a las que nos hemos acostumbrado, pero en las que no es fácil encontrar un sitio familiar y acogedor. No ofrecen un sentimiento de pertenencia moral. También se pierde el sentido de la política como servicio al ser humano. La política se convierte en técnica y el Estado obedece a los grandes monopolios. La ciencia y la tecnología han tenido y tienen logros importantes, pero construyen una sociedad sin ética. Faltan estructuras y ligaduras más profundas que unan a las personas por medio de los valores éticos. La masa se olvida de la ética; es decir, de las buenas relaciones entre los individuos, de la amistad. ¿Quién prospera en una sociedad sin ética? El jefe de una banda de gangsters, el impositor, el especulador, tal vez el bufón si encuentra un señor que lo proteja, pero no el ciudadano, porque ya no existe (Dahrendorf, 2006, pp. 105-125).

El filósofo Jürgen Habermas hace la importante acotación de que la Posmodernidad cuestionó las ideologías de los grandes relatos o explicaciones de la sociedad, con excepción de la ideología del positivismo de la ciencia y de la tecnología. La desconstrucción no afectó a la ciencia. Los conceptos éticos quedan reemplazados por la normalidad de la biología, sociología, psicología, economía, administración y tecnología. Sin embargo, las ciencias verifican los «datos», no el «valor». Vivimos el fisicalismo, el fisiologismo, el sociologismo, etc. Esta sobrevaloración de la naturaleza influye en la política, en la ética y en el comportamiento del ser humano. En la naturaleza está la norma del bienestar del ser humano. La naturaleza se vuelve un concepto sagrado.

Se pierde el origen de la ética que está en el cambio de la persona, en la decisión libre para buscar el bien.

Con su trabajo el hombre ha de procurarse el pan cotidiano, contribuir al continuo progreso de las ciencias y la técnica, y sobre todo a la incesante elevación cultural y moral de la sociedad en la que vive en comunidad con sus hermanos. (Juan Pablo II, 1982, Introducción). 
La elevación justa y moral permite la relación justa y humana con los otros a partir de la moral interna de cada uno.

En segundo lugar, el bienestar material puede ayudar a la liberación del ser humano, pero no causarla. El hombre tiene la capacidad, la libertad, de superar la naturaleza y la historia. La libertad permite transcender al materialismo. También transciende a la ciencia que se limita al entorno material. La persona es inteligente y libre. Tengo un espacio interior propio. Puedo reflexionar sobre mí mismo.

En la meditación tomo posición frente a mi vida, en cierto sentido me retiro de mi vida, pero no como un conocimiento puro, sino reflexiono sobre mí, sobre lo que soy o debería ser. No soy mi vida, pero si tengo la posibilidad de juzgarla es por la condición de poder meditar encima de todo juicio. (Marcel, 1949, pp. 63-64)

Soy un ser espiritual y transciendo lo material. La libertad es del orden espiritual. Encontramos en nosotros mismos un núcleo espiritual que nadie puede negar o eliminar. Es la libertad de la persona. La persona se autodetermina, es fuente de sus propios actos. Por la libertad una persona decide sobre la propia realización de su vida. La primera persona con quien uno se relaciona es consigo mismo. Somos responsables de nosotros mismos. El ser humano tiene la posibilidad y la obligación de cultivar su propia persona, el amor propio. Es la confianza en mí mismo. El amor propio es la condición para poder amar a los demás. Los deseos y necesidades son también espirituales.

Por autorreflexión, llamada la conciencia, podemos descubrir en nosotros la existencia de los valores. Los fines, ideales o valores juegan el mismo papel que los principios en las ciencias. Los valores son los criterios básicos de orientación para las decisiones prácticas sobre la vida: justicia, fortaleza, templanza, agradecimiento, lealtad, solidaridad, perdón, misericordia, etc. La libertad responsable implica cultivar en nosotros estos valores para que podamos establecer buenas relaciones con los demás. Estas relaciones son las ligaduras entre los seres humanos y permiten encontrar el sentido de la vida. 
Aristóteles señala que el matrimonio es agradable cuando hombre y mujer tienen dignidad; es decir, practican los valores. Ellos son el resultado de una decisión libre, pero la libertad necesita una convicción. La convicción no existe por sí misma, ha de ser conquistada siempre de nuevo. El filósofo André Comte-Sponville sostiene que una moral que se limita a denunciar es una moral de gente triste. El que solo denuncia y no presenta soluciones promueve el complejo de inferioridad. El ser humano debe renovar siempre su fe en los ideales o valores para adquirir la convicción que oriente su libertad hacia el bien. La persona que siempre opta por el bien adquiere una actitud correcta; es decir, el valor se vuelve costumbre o virtud. Es la persona confiable. Aristóteles nombra a la justicia como la mejor de las virtudes, pero llama a la prudencia la virtud por excelencia. La prudencia, hoy llamada conocimiento práctico, pertenece a la parte intelectual del ser humano. El conocimiento práctico es la capacidad que nos indica cómo debemos aplicar las virtudes morales en el laberinto de la vida. Es una deliberación y no una reflexión. Una ética sin conocimiento práctico es una ética sin sentido o peligrosa.

La prudencia es más amplia que la aplicación de una teoría científica porque se refiere a la totalidad de los actos prácticos del ser humano, es nuestra forma de vida. John Henry Newman decía que la ciencia de la vida, para los casos concretos, nunca se ha escrito y nunca se podrá escribir. Benedicto XVI afirmaba que el amor es rico en inteligencia y la inteligencia llena de amor.

En tercer lugar, los gobiernos actuales declaran que el ser humano tiene plena libertad en su vida privada y no se pronuncian sobre los valores morales. La filósofa estadounidense Martha Nussbaum ha señalado que esta postura neutral ha sido particularmente negativa para las familias y sobre todo para la educación de los hijos (Nussbaum, 2011, p. 45). Los gobiernos se declaran neutrales en cuanto a su relación con la vida privada. La pregunta es si se puede hacer una separación radical entre la vida privada y la vida pública. Nadie dudaba antes de la existencia de Dios y todos pertenecían a alguna iglesia. En la sociedad actual, esta evidencia ha sido reemplazada por la mentalidad científica y tecnológica que domina nuestras esferas pública y privada. La ciencia y la tecnología cambiaron el conocimiento de la sociedad, pero también cambiaron los intereses de la persona privada. No hay 
separación entre vida pública y vida privada. Los adultos se encuentran con otros adultos en el trabajo, los hijos con sus pares en los centros educativos, y todos están en contacto con los medios de comunicación, con la publicidad, con las leyes, con el Gobierno, con el mercado. La ideología de la tecnología es omnipresente. Víctima principal es la familia.

Al reflexionar sobre nosotros mismos encontramos los valores en nuestra conciencia. Recibimos la capacidad de distinguir y decidir entre el bien y el mal. La decisión está dentro del sujeto. La persona se educa a sí misma, asimila los valores, para poder compartirlos con los demás. Es el sentido del amor propio. De esta manera, las normas no son exteriores o impuestas. Los valores dependen de una conciencia y de una actitud previa a las obligaciones y responsabilidades, pero la conciencia necesita también un ambiente donde se aprendan los valores por experiencia.

Un problema muy urgente en el mundo actual es la amenaza a la familia y al matrimonio por el poderoso mensaje materialista de la ideología de la tecnología que eliminó todas las culturas y logró hacer un ser humano homogéneo, sin conciencia de los verdaderos valores que unen a las personas. Se entiende tolerancia como no tener una convicción propia. El divorcio, el amor libre, el egoísmo y el hedonismo son ocurrencias del momento. Hay una preocupación por la familia en las iglesias y en muchas filosofías del ateísmo porque consideran que es el fundamento de la sociedad. Trescientos años antes de Cristo, el filósofo Aristóteles decía que los padres aman a los hijos y los hijos aman a los padres. Estos les enseñan cómo deben vivir, cómo deben comportarse con otras personas. «No es, pues, de poca importancia contraer desde la infancia y lo más pronto posible tales o cuales hábitos; por el contrario, es este un punto de muchísimo interés, o por mejor decir, es todo» (Aristóteles, 2004, II, 1).

La actitud del amor traerá todas las otras virtudes, como dar a cada uno lo suyo, aprender a luchar en la vida y saber sacrificarse, porque vivir con otros incluye respetar sus derechos. El amor de los padres a los hijos no se manifestará por decretos y comunicados, sino por el ejemplo entre varón y mujer. Siempre somos ejemplos, para el bien o para el mal (Gomá, 2009, p. 227). Por el testimonio de amor entre los padres y de los padres hacia los hijos la persona aprende a valorar la vida, la libertad, la paz, la justicia, 
el respeto, la lealtad y el agradecimiento. Se aprende a controlar emociones de egoísmo, envidia, odio, resentimiento, narcisismo, alcoholismo y drogas (Nussbaum, 2014, p. 154). No se puede poner en duda el significado políticomoral de la esfera familiar, puesto que las condiciones psíquicas para casi todas las actitudes que el individuo debe tener en virtud de sus competencias y sus habilidades individuales, para interceder por los asuntos de la comunidad mayor, amén de todos sus vínculos con comunidades particulares, se crean dentro de familias intactas, confiables e igualitarias (Honneth, 2014, p. 229). El ejemplo y las orientaciones de los padres son también el modelo que servirá a los hijos para lograr un buen matrimonio en el futuro.

Esta educación en la comunión familiar es un servicio fundamental a la sociedad para que los hijos se incorporen a ella como ciudadanos honestos, dedicados al estudio en los centros educativos, comprometidos con su trabajo, respetuosos de las leyes, promotores del bien, de los derechos humanos y de la dignidad de todos. «Digo solamente que si la revolución del amor se inicia en el matrimonio primeramente, ella se prolonga por una refracción en el plano colectivo, público y político» (Ferry, 2009, p. 139). Los que no reciben este fundamento serán personas conflictivas en la sociedad: egoístas, engreídos, corruptos, resentidos, perpetradores de bullying escolar, delincuentes, drogadictos, etc.

La preponderancia de la ideología de la tecnología ha llevado a los ministros de educación a eliminar las ciencias sociales, el arte, la ética y la religión de los sílabos académicos. No obstante, el ser humano sin arte será un autómata, y sin ética no sabrá convivir con otros.

En cuarto lugar, el sentido de la vida no se logra por cualquier relación con la materia. El origen y el fin del Estado están constituidos por la justicia y la justicia es de naturaleza ética. Los problemas no se resuelven solo con promulgar leyes y normas. Se necesita la práctica de los valores porque ellos abarcan también las macrorrelaciones políticas y los grandes mecanismos productivos, financieros y comerciales. La justicia es un concepto filosófico de la ética. Por lo tanto, existe una prioridad de la ética sobre la técnica y la política, una superioridad del espíritu sobre la materia. El desarrollo humano integral supone una libertad responsable de la persona. Ninguna 
estructura puede garantizar dicho desarrollo desde afuera y por encima de la responsabilidad humana. Todas las situaciones de desarrollo o subdesarrollo no son una necesidad histórica, sino dependen de esta responsabilidad. La persona puede fracasar en su vida si no actúa con responsabilidad. Se considera que la solución actualmente está en recuperar las instituciones. Sin embargo, ellas no serán una solución si no son dirigidas por seres humanos honestos. La justicia debe ser el principio tanto para las microrrelaciones como para las macrorrelaciones económicas, políticas y sociales. Para poder realizarse, la libertad necesita cumplir con los valores o normas. Finalmente, el desarrollo es imposible sin seres humanos rectos, sin operadores económicos y agentes políticos que sientan fuertemente en su conciencia la llamada al bien común.

Ya Aristóteles señalaba que el hombre puede distinguir entre el bien y el mal, y que su realización no es automática, sino que depende de sus decisiones por el bien y de los ejemplos. El sentido de la vida es profundamente ético. «La felicidad es una actividad del alma» (Aristóteles, 2004, I, 13). Hasta el siglo XVIII se mantenía la ejemplaridad personal. En el transcurso de la Ilustración, la razón hizo desaparecer la teoría del ejemplo y de la imitación. A partir de entonces la ley abstracta reemplaza al ejemplo de las autoridades políticas. Se pierde el poder del ejemplo que añade el poder atractivo al poder directivo. Javier Gomá sostiene que los políticos gobiernan de dos maneras: produciendo leyes y produciendo costumbres. Una cosa es lo que los políticos ordenan (coacción) y otra lo que ellos son (ejemplos). Las leyes coaccionan a los ciudadanos, pero los ejemplos entran en el corazón y lo reforman. Podría decirse que la política es el arte de ejemplificar (Gomá, 2009, p. 179).

La caridad y la verdad son los principios necesarios para que las grandes economías estén al servicio del bien común. «Toda decisión económica tiene consecuencias de carácter moral» (Benedicto XVI, 2009).

En quinto lugar, se intenta resolver este problema imponiendo reglamentos para todo y comités de ética. Los comités son importantes, pero no pueden denominarse «de ética» porque les falta el factor de la voluntad libre para hacer el bien. Si la persona no busca el bien por convicción, las reglas no servirán porque no cubren toda la realidad de la vida, y además 
la persona indiferente trata de evitarlas (van Tongeren, 2008, p. 30). A pesar de los distintos enfoques económicos, las ideologías coinciden en una moral relativista. Se pierde el origen de la ética que está en la conciencia personal formada sobre la base de valores. Las ideologías afirman la autonomía absoluta del hombre, independientemente de una supuesta realidad sobrenatural. Sin embargo, ser cada día más verdaderos significa cambiar nuestra falsa conciencia de que somos dueños absolutos de nosotros mismos y llegar al conocimiento claro de que hemos recibido nuestra existencia. La primera pregunta no es ¿qué voy a hacer?, sino ¿quién soy yo?

\section{Solo el misterio del amor puede superar la contradicción entre naturaleza y cultura}

Existe una corriente en la Iglesia que explica el abandono de muchos fieles por la falta de adaptación de esta institución a las conquistas de la Modernidad, así como por el escándalo de los sacerdotes pedófilos. Sin embargo, el problema es más profundo. En 1965, ya podíamos leer lo manifestado en la Constitución Pastoral Gaudium et Spes del Concilio Vaticano II:

Por otra parte, muchedumbres cada día más numerosas dejan de practicar la religión. Negar a Dios y a la religión, prescindir totalmente de ellos, no constituye ya, como en el pasado, un hecho raro e individual: actualmente, con frecuencia, se presentan como exigencias del progreso científico o como un nuevo tipo de humanismo. (Concilio Vaticano, 1965, II, 7)

Nos encontramos con una contradicción entre un pensamiento que considera que todo ha sido construido por el ser humano y la ciencia positiva que opta por reducir todo a la naturaleza dada. Existe una dualidad entre naturaleza y cultura. La teología afirma que la naturaleza es una creación de Dios. Cultura y naturaleza son entendidas como participativas en la revelación de Dios. En lugar de estar frente a la historia, tiempo y cambio, la verdad es un acontecimiento en el cual actos, pensamientos e imaginaciones participan en lo divino. La naturaleza y la cultura no son exclusivamente inmanentes. El relato de una historia desde su origen supera la dualidad de una explicación científica y de una subjetividad ficticia. Este 
relato es una historia de salvación. Solo el misterio del amor puede superar la contradicción moderna entre naturaleza y cultura. La paz no es solo producto de investigación científica, de producción tecnológica, de experiencia individualista y de lucha por la justicia. Solo se puede lograr la paz cuando el hacer y el pensamiento humano están comprendidos como amor en una historia de salvación (Grey, 2015, pp. 325-337).

Se necesita una crítica, y sobre todo una autocrítica, a las ideologías que no quieren escuchar, a los planes educativos que han eliminado toda referencia a la ética, a los elogios al hedonismo, a la autonomía absoluta de la ciencia y de la técnica. Se necesita una nueva valoración de la familia y del centro educativo, que son las fuentes de la educación en valores. Ya Aristóteles afirmó en contra de Platón que la pertenencia y el amor en la familia reducirían al mínimo los enfrentamientos civiles.

No podemos avanzar en el difícil camino de la transformación de la vida económica si no realizamos una verdadera conversión de mentalidades y corazones. El universo es sordo e indiferente para amor, esperanzas y sufrimientos. ¿Si Dios no existe como fuente de todos los valores, cómo puedo entonces encontrar algo que le dé valor a la existencia?

Si hay paganos que cumplen la ley, es porque la ley está inscrita por Dios en sus corazones (San Pablo, Romanos, 2, 13-16). Ya hemos citado la afirmación de Maalouf (2019) en el sentido de que la brújula ética representa el principio de igualdad. Sin embargo, la igualdad no es suficiente como principio de la sociedad porque puede llevar a inercia o envidia si no va acompañada por un ideal, por el amor que busca el bien y lleva la persona a hacer el bien. El problema actual es una inteligencia que entiende los gestos a partir de intereses por la mentalidad utilitarista y el egoísmo. La inteligencia no está entrenada para una experiencia de gratuidad.

Todas las virtudes dependen del amor porque solo el ser humano que tiene la pasión del amor se preocupa en cumplir con todas las personas. Sin el amor la justicia tiende a ser egoísta, reclamo de mi interés o de mi partido. Tomás de Aquino decía que la justicia sin amor es crueldad. La nueva definición de la vida es el amor. El amor es la unidad perfecta de verdad, de bien y de belleza. 


\section{«Mi corazón se conmueve y se remueven las entrañas»}

Dios le dio libertad al hombre para asumir su propia responsabilidad y desarrollar su vida; sin embargo, este tiende olvidarse de su origen. Israel ha cometido «adulterio»; es decir, abandonó a Dios, quien debería juzgarlo y repudiarlo. Pero en esto se revela que Él es Dios y no hombre: «Cómo voy a dejarte abandonado Efraím? ¿Cómo no te voy a rescatar, Israel? (...) Mi corazón se conmueve y se remueven las entrañas. No puedo dejarme llevar por mi indignación y destruir a Efraím, pues soy Dios y no hombre. Yo soy el Santo en medio de ti, y no me gusta destruir» (Oseas, 11, 7-10; Juan, 4, 10). El amor de Dios para los seres humanos es un acto libre, eterno, estable y definitivo (Durand, 2019, p. 133).

Cristo irrumpió en la historia para que el hombre vuelva a descubrir el verdadero sentido de su existencia. «Como el Padre me amó, así también los he amado Yo: permanezcan en mi amor» (San Juan, 15, 9-10). El ejemplo de Jesucristo -no hay amor más grande que dar la vida por los amigostransforma nuestros pensamientos y emociones. Cristo es la fuente de una conciencia que el mundo tecnológico considera superflua. La vida del cristiano parte de una ética de amar; es decir, buscar y hacer el bien.

«Lo que somos es obra de Dios: hemos sido creados en Cristo Jesús con miras a las buenas obras que Dios dispuso de antemano para que nos ocupáramos en ellas» (Efesios, 2,10). «No sigan la corriente del mundo en que vivimos, sino más bien transfórmense a partir de una renovación interior. Así sabrán distinguir cuál es la voluntad de Dios, lo que es bueno, lo que agrada, lo que es perfecto» (Romanos, 12, 2).

La corriente del mundo actual es la utilidad, que trae el egoísmo, odio y envidia. «Si uno dice: yo amo a Dios y odia a su hermano, es un mentiroso. Si no ama a su hermano a quien ve, no puede amar a Dios a quien no ve» (I Juan, 4, 20). «Una cosa es cierta, y en ella debes insistir: los que creen en Dios han de destacarse en el bien que pueden hacer» (Tito, 3, 8). «Que cada uno busque lo que agrada a su prójimo, ayudándole a crecer en el bien» (Romanos, 15, 2). «Pero ustedes, hermanos, no se cansen de hacer el bien» (II Tesalonicenses, 3, 13). «Por consiguiente, mientras tengamos la oportunidad, hagamos el bien a todos, y especialmente a los de la casa, que son nuestros hermanos en la fe» (Gálatas, 6, 10). 
San Pablo felicita a las comunidades de tesalonicenses y filipenses por la fe en Dios y por el bien que hacen. «Pido que el amor crezca en ustedes junto con el conocimiento y la lucidez para que puedan discernir en toda circunstancia» (Filipenses, I, 9). «Cumplan con todo sin quejas ni discusiones; así no tendrán falla ni defecto y serán hijos de Dios sin reproche en medio de una generación descarriada y pervertida. Ustedes son la luz en medio de ellos, como las estrellas en el universo, al presentarles la palabra de vida» (Filipenses, II, 14-16). «Ustedes se hicieron imitadores nuestros y del mismo Señor. Empezaron a servir al Dios vivo y verdadero. Que el Señor los haga crecer más y más en el amor que tienen unos a otros y el amor para con todos, imitando el amor que sentimos por ustedes» (Tesalonicenses, 3, 12).

Juan y Andrés, los dos primeros que siguieron a Jesús, aprendieron a conocerse de un modo distinto, a transformarse ellos mismos y a cambiar su realidad por el seguimiento de aquella persona excepcional. En la vida uno puede encontrarse con alguien que más tarde tendrá un significado decisivo en nuestra existencia. En la época contemporánea la persona no está contemplada como instrumento de conocimiento y cambio. Se considera imposible conocerse y cambiarse a sí mismo y a la realidad «solo» siguiendo a una persona. Sin embargo,

(...) se ha de destacar que las verdades buscadas en esta relación no pertenecen primeramente al orden fáctico o filosófico. Lo que pretende, más que nada, es la verdad misma de la persona: lo que ella es y lo que manifiesta de su propio interior. En efecto, la perfección del hombre no está en la mera adquisición de conocimiento abstracto de la verdad, sino que consiste también en una relación viva de entrega y fidelidad hacia el otro. En esta fidelidad que sabe darse, el hombre encuentra plena certeza y seguridad. Al mismo tiempo, el conocimiento por creencia, que se funda sobre la confianza interpersonal, está en relación con la verdad: el hombre creyendo confía en la verdad que el otro le manifiesta. (Juan Pablo II, 1998, p. 32)

La Iglesia declara que la familia es la Iglesia doméstica. La frase central de la Revelación, «Dios ama a su pueblo», es pronunciada a través de las frases vivas concretas con que el hombre y la mujer se declaran su amor conyugal. 
La esposa busca agradar al esposo y el esposo busca agradar a la esposa (I Corintios, 32-34). La espiritualidad del amor familiar está hecha de miles de gestos reales y concretos. El testimonio de fe y de amor entre los padres, originado en el amor de Cristo a la Iglesia, se transmite a los hijos. El Espíritu que infunde el Padre renueva nuestro corazón y hace al varón y a la mujer capaces de amar como Cristo nos amó. Cristo va al encuentro de ellos para otorgar la gracia de hacer el bien. La persona humana tiene una innata y estructural dimensión social, y el matrimonio y la familia son el fundamento de la sociedad como instancia primera y decisiva. La salvación de la persona y de la sociedad humana y cristiana se halla estrechamente ligada con la felicidad misma de la comunidad conyugal y familiar.

Todo es del hombre porque el hombre es sujeto de su existencia. Y a la vez es de Dios porque Él es el principio y el fin de todo lo que tiene valor y nos redime: «el mundo, la vida, la muerte, lo presente, lo futuro. Todo es suyo, ustedes de Cristo, y Cristo de Dios» (I Corintios, 3, 22-23). Todo proviene de la caridad de Dios, todo adquiere forma por ella, y a ella tiende todo.

\section{Referencias}

Aristóteles. (2004). Ética Nicomáquea. Losada.

Benedicto XVI. (2006). Encíclica Deus caritas est. Paulinas Epiconsa.

Benedicto XVI. (2009). Encíclica Caritas in veritate. Paulinas Epiconsa.

Concilio Vaticano II. (1965). Gaudium et Spes.

Cortina, A. (2008). Ética sin moral. Tecnos.

Dahrendorf, R. (2006). El recomienzo de la historia. Katz.

Durand, E. (2019). Les émotions de Dieu. Du Cerf.

Ferry, L. (2006). Apprendre à vivre. Plon.

Ferry, L. (2009). Face à la crise. Odile Jacob.

Francisco. (2015). Encíclica Laudato si'. Paulinas Epiconsa.

Gomá, J. (2009). Ejemplaridad pública. Santillana.

Grey, C. (2015). Alleen de theologie kan de cultuur redden. Tijdschrift voor Theologia. Boom.

Habermas, J. (2000). Aclaraciones a la ética del discurso. Trotta.

Habermas, J. (2013). Ciencia y técnica como «ideología». Tecnos.

Harari, Y. N. (2015). Homo Deus. Penguin Random House.

Hedges, C. (2008). Ik geloof niet in atheisten. Meulenhof. 
Honneth, A. (2014). El derecho a la libertad. Katz.

Juan Pablo II. (1982). Encíclica Laborem exercens. Paulinas Epiconsa.

Juan Pablo II. (1998). Encíclica Fides et ratio. Paulinas Epiconsa.

Leuridan, J. (2021). El sentido de las dimensiones éticas de la vida. Generis Publishing.

Maalouf, A. (2019). El naufragio de las civilizaciones. Alianza Editorial.

Marcel, G. (1949). Position et Approches Concrètes du Mystère Ontologique. Vrin.

Michéa, J-L. (2007). L'Empire du moindre mal. Climats.

Nietzsche, F. (2017). La genealogía de la moral. Alianza.

Murdoch, I. (1969). On «God» and «Good». Chatto \& Windus.

Nussbaum, M. (2011). Creating Capabilities. Belknap Press of Harvard.

Nussbaum, M. (2014). Emociones políticas. Espasa Libros.

van Tongeren, P. (2008). Een inleiding in de deugdenethiek. Ed. Sun. 